\title{
INHALATORY ANESTHESIA WITH LARYNGEAL MASK IN A BROCKET DEER (Mazama gouazoubira)
}

\author{
VILANI, R.G.D'O.C. ${ }^{1}$; MANGINI, P.R. ${ }^{1}$; ROSA, D.B.S. ${ }^{2}$;ORZATO, M.M. ${ }^{2}$ \\ ${ }^{1}$ Pontifícia Universidade Católica do Paraná; \\ ${ }^{2}$ Graduando PUC-PR.
}

Among the instruments recently used in Veterinary Anesthesiology, the laryngeal mask is a device that provides to the patient maintenance of the permeability of the air tract ducts. Its use is simpler when compared with the endotracheal tube due to uncomplicated insertion and trauma impossibility because the laryngoscopy is not needed avoiding stimulation of the vagus nerve. When compared to the facial mask the laryngeal mask provides larger safety for enabling effective assisted ventilation. The aim of the present communication is to describe an inhalatory anesthesia by the utilization of a laryngeal mask in a $15 \mathrm{~kg}$ adult female deer-"catingueiro" (Mazama gouazoubira), from the Centro de Triagem de Animais Silvestres - Vivat Floresta - of the Pontifícia Universidade Católica do Paraná. Chemical restraint for cage transfer and blood and feces samples collection was carried out with $100 \mathrm{mg}$ of total dose of an association of tiletamine hydrochloride and zolazepam applied intramuscularly. After fifteen minutes the animal remained in a lateral recumbence with shallow and eyelid reflexes. The anesthetic complementation was then performed with halothane by means of a facial mask during three minutes. The laryngeal mask is then inserted in the first attempt and connected to a semi-closed inhalatory anesthesia circuit device during 60 minutes. The vital signs of the patient were periodically checked out through respiratory and heart rates and internal temperature. The laryngeal mask was removed 2 minutes after the end of the anesthetic administration, the shallow and head movement reflexes returning immediately after. The use of the laryngeal mask was simple and practical allowing safety and efficiency to the anesthetic act. It showed to be an excellent option for the permeability air tract ducts maintenance in this specie.

Key Words: laryngeal mask, permeability, Mazama gouazoubira, inhalatory anesthesia. 